\title{
Clinical evaluation of postmenopausal bleeding at a tertiary care center
}

\author{
Jyothsna Sravanthi ${ }^{1}$, S Lavanya $^{2 *}$, A Lakshmi Prasanna ${ }^{3}$, Gali Niroosha ${ }^{4}$
}

Department of Obstetrics and Gynaecology, Narayana Medical College, Nellore, Andrea Pradesh, INDIA. Email: lavsowji68@gmail.com

Abstract Background: In this era, as life expectancy is increasing women are experiencing a longer postmenopausal phase. Postmenopausal bleeding is an alarming symptom in this age group although only $10 \%$ of postmenopausal women have postmenopausal bleeding. In developed countries the risk of endometrial cancer in postmenopausal bleeding women is high whereas risk of cervical cancer is higher in developing countries. This prospective study was carried out on 82 consecutive patients presenting with postmenopausal bleeding attending gynaecology Clinic at a tertiary care center. Material and Methods: The present study was a hospital based prospective study conducted in the department of Obstetrics and gynaecology in post-menopausal women with complaints of per vaginal bleeding. Results: After applying inclusion and exclusion criteria, 82 patients were selected for present study. Most patients had menopause after 45 years (84\%), only $16 \%$ were from age group 40-45 years. We noted that Age of postmenopausal bleeding (years) was 50-60 years in $56 \%$ patients followed by $30 \%$ in $>60$ years age. $66 \%$ patients had $>2$ parity. Hypertension $(20 \%)$, Diabetes mellitus (11\%), Overweight (50-100kg) $(22 \%)$, Obesity (>100kg) $(4 \%)$, Hypothyroidism $(4 \%)$ were common medical problem in present study. In present study $57(70 \%)$ cases were benign, while $25(30 \%)$ were malignant. Proliferative $(22 \%)$, atrophic $(13 \%)$, cystoglandular hyperplasia $(10 \%)$, endometrial hyperplasia $(9 \%)$ were common benign conditions and well differentiated squamous cell carcinoma (16\%) and well differentiated endometrioid type $(6 \%)$ were common malignant conditions. Conclusion: Apart from common benign lesions, carcinoma cervix and carcinoma endometrium are commonly seen in postmenopusal women with complaints of postmenopausal bleeding. Early diagnosis can certainly improve quality life and reduce mortality and morbidity.

Keywords: Post menopausal bleeding, Cervical Carcinoma, Endometrial thickness, Endometrial carcinoma.

*Address for Correspondence:

Dr. S. Lavanya, Associate Professor, Department of Obstetrics and Gynaecology, Narayana Medical College, Nellore, Andrea Pradesh.

Email: lavsowji68@gmail.com

Received Date: 20/12/2019 Revised Date: 11/01/2020 Accepted Date: 04/02/2020

DOI: https://doi.org/10.26611/10121431

\begin{tabular}{|l|l|}
\hline \multicolumn{2}{|c|}{ Access this article online } \\
\hline Quick Response Code: & Website: \\
& www.medpulse.in \\
\hline & \\
\hline
\end{tabular}

\section{INTRODUCTION}

WHO has defined postmenopausal bleeding (PMB) as an episode of bleeding twelve months or more after the last menstrual period following menopause resulting from loss of ovarian activity. ${ }^{1}$ Average age at menopause in Indians is around 45 to 50 years ${ }^{1}$. In this era, as life expectancy is increasing women are experiencing a longer postmenopausal phase. Postmenopausal bleeding is an alarming symptom in this age group although only $10 \%$ of postmenopausal women have postmenopausal bleeding $^{2}$. It accounts for a significant proportion of gynecological referrals due to suspicion of underlying malignancy. Cervical cancer is the fourth most common cancer in the world and India alone accounts for $25 \%$ of its burden worldwide. Nearly $70 \%$ of the women with cervical cancer presents to the hospital at advanced stages where the 5 -year survival rate is only $50 \%{ }^{3}$. Cervical cancer is one of the common malignancies presenting as postmenopausal bleeding in developing countries. Premalignant and malignant lesions of the cervix may also present as postmenopausal bleeding ${ }^{4}$. In developed countries the risk of endometrial cancer in postmenopausal bleeding women is high whereas risk of cervical cancer is higher in developing countries5. Endometrial and cervical cancers if detected early, can be cured completely. Endometrial hyperplasia is one of the 
most important predisposing factors for the development of endometrial carcinoma. Atypical endometrial hyperplasia has a higher risk of malignant transformation than with endometrial hyperplasia without atypia ${ }^{5}$. This prospective study was carried out on 82 consecutive patients presenting with postmenopausal bleeding attending Gynaecology Clinic at a tertiary care center.

\section{MATERIAL AND METHODS}

The present study was a hospital based prospective study conducted in the department of Obstetrics and Gynaecology from August 2018 to September 2019. Approval was taken from Institutional ethical committee for present study.

\section{Inclusion Criteria}

Post-menopausal women with complaints of per vaginal bleeding.

\section{Exclusion Criteria}

Patients with bleeding disorders/blood dyscrasias. Patients on anticoagulant therapy. Premature menopause whether surgical, natural, radiation or Chemotherapy induced. Age less than 40 years. Patients on hormone replacement therapy. Injuries to genital tract.

Written and informed consent was taken. The history of postmenopausal bleeding varied from spotting per vagina, brownish discharge, scanty flow and moderate to profuse bleeding, presenting six months or more after menopause. Patients were evaluated by history, clinical examination and investigations like abdominal/transvaginal sonography, endometrial biopsy done with fractional curettage, Papanicolau smear, cervical biopsy, hysteroscopic guided biopsy if required was done for all subjects. In few of the cases simultaneous endometrial and cervical biopsies were done. Later few patients underwent hysterectomy. Histopathology reports for present study were collected from the endometrial, cervical biopsies and hysterectomy specimens sent for histopathological examination to the department of Pathology. Data was collected in proforma, entered in Microsoft excel sheet and analysed.

\section{RESULTS}

After applying inclusion and exclusion criteria, 82 patients were selected for present study. Most patients had menopause after 45 years (84\%), only $16 \%$ were from age group 40-45 years. We noted that Age of postmenopausal bleeding (years) was 50-60 years in 56\% patients followed by $30 \%$ in $>60$ years age. $66 \%$ patients had $>2$ parity. Hypertension $(20 \%)$, Diabetes mellitus (11\%), Overweight (50-100kg) (22\%), Obesity (>100kg) (4\%), Hypothyroidism (4\%) were common medical problem in present study.

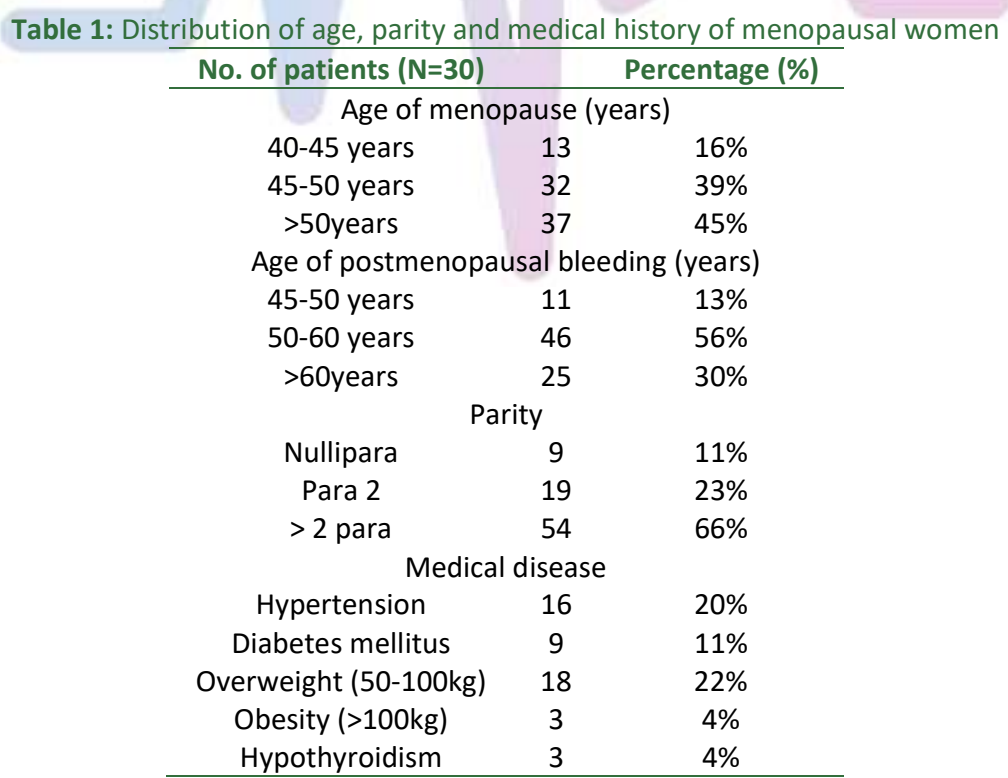

In present study 57 (70\%) cases were benign, while 25 (30\%) were malignant. Proliferative (22\%), atrophic (13\%), cystoglandular hyperplasia (10\%), endometrial hyperplasia (9\%) were common benign conditions and well differentiated squamous cell carcinoma (16\%) and well differentiated endometrioid type (6\%) were common malignant conditions. 
Table 2: Histopathological findings

\begin{tabular}{ccc}
\hline Histopathological findings & No. of patients & Percentage (\%) \\
\hline Benign & 57 & $70 \%$ \\
Proliferative & 18 & $22 \%$ \\
Atrophic & 11 & $13 \%$ \\
Cystoglandular hyperplasia & 8 & $10 \%$ \\
Endometrial hyperplasia & 7 & $9 \%$ \\
Endometritis & 6 & $7 \%$ \\
Fibroids & 4 & $5 \%$ \\
Endometrial polyp & 3 & $4 \%$ \\
Malignant & 25 & $30 \%$ \\
Cervical carcinoma & 15 & $18 \%$ \\
Well differentiated squamous cell carcinoma & 13 & $16 \%$ \\
Moderately differentiated squamous cell carcinoma & 2 & $2 \%$ \\
Endometrial carcinoma & 9 & $11 \%$ \\
Well differentiated endometrioid type & 5 & $6 \%$ \\
Moderately differentiated & 2 & $2 \%$ \\
Villoglandular type & 1 & $1 \%$ \\
Poorly differentiated & 1 & $1 \%$ \\
\hline
\end{tabular}

\section{DISCUSSION}

Postmenopausal bleeding is a sinister complaint of postmenopausal women. It is common between 5-10years after reaching menopause and common age predilection is between 50-60 years. ${ }^{6}$ Etiology of post menopausal bleeding includes benign causes like proliferative or atrophic endometrium, endometrial polyp or cervical polyp, endometrial hyperplasia (simple, complex with or without atypia) and malignant causes like endometrial carcinoma, cervical carcinoma, uterine sarcoma, estrogen secreting ovarian tumors, vaginal and vulval carcinoma. Rare causes are chronic endometritis of tuberculosis, thrombocytopenia, leukemia, usage of anticoagulants and secondary coagulopathy from liver disease. Even though the most frequent causes of post menopausal bleeding are benign conditions, it is important to exclude atypical hyperplasia and endometrial carcinoma by thorough investigations. Patient characteristics like multiparity, early marriage, multiple sexual partners are risk factors for cervical cancer; advanced age, obesity, early menarche, late menopause, hypertension, diabetes mellitus, nulliparity etc., can increase the probability of having endometrial cancer in patients with post menopausal bleeding. Post menopausal bleeding has been evaluated by clinical examination, pelvic ultrasound, investigations like pap smear and fractional curettage in this study. Ultrasound pelvis is an appropriate first-line procedure to identify which woman with post-menopausal bleeding is at higher risk of endometrial cancer. In general, the thicker the endometrium, the higher the probability of important pathology i.e. endometrial cancer being present. Transvaginal ultrasonography (TVS) is the recommended first line non invasive procedure for assessing the endometrium in women with PMB. Measurement of endometrial thickness by TVS having a cut off of $>4 \mathrm{~mm}$ yields $98 \%$ sensitivity for detection of endometrial carcinoma. Hysteroscopy and biopsy (curettage) is the preferred diagnostic technique to detect benign lesions. As such there are several investigations available to complement clinical evaluation, including ultrasound, endometrial histology and hysteroscopy to evaluate the underlying etiology of $\mathrm{PMB}^{7}$. The office vaginoscopic hysteroscopy is populated as replacing for traditional approach especially in postmenopausal women due to it is performed without vaginal speculum, neither cervical tenaculum nor cervical dilatation. The patient requires no systemic sedatives or medications as the procedure is usual painlessly, no injury to vaginal outlet. ${ }^{8,9}$ Women with PMB has a $10 \%$ risk of having genital malignancies such as cervical cancer, endometrial cancer, vaginal, ovarian, and vulval cancers along with a $10 \%$ risk of significant pathology ${ }^{10}$. Although PMB is often associated with benign pathologies, the possibility of having an underlying malignancy makes it a sinister complaint requiring thorough clinical work up. Evidence has shown that early detection of cervical and endometrial cancer improves the cure rate and reduces mortality ${ }^{11}$.A community-based cross-sectional study conducted by Aswathy et al. in Rural Kerala and a hospital-based study conducted by Harsha Kumar in Mangalore also reported a low screening level of $6.9 \%$ and $7.2 \%$, respectively. ${ }^{12,13}$ Most patients had menopause after 45 years $(84 \%)$, and age of postmenopausal bleeding was 50-60 years. The duration of menopause before the onset of postmenopausal bleeding ranged from 2-17 years and the majority of them presented after 5 years of cessation of normal menstruation. This is in correlation with the studies done by Ubeja et $a l^{2}$. We noted that carcinoma cervix was most common malignancy, also noted by various other Indian studies, while endometrial carcinoma as the most common malignant cause for postmenopausal bleeding was noted by Sonali Rathi etal5 and Arati mallick ${ }^{16,17}$.Among the 454 postmenopausal patients in one of the study, final diagnosis was cancer cervix in $6.6 \%$ cases, atypical hyperplasia in $0.2 \%$, hyperplasia without atypia in $2 \%$, polyps in $37.7 \%$, fibroid in $6.2 \%$, proliferative/secretory in 
$14.5 \%$ and hypertrophy/atrophy in $30.8 \%$ cases $^{18}$. The complex atypical hyperplasia has $25-30 \%$ incidence of progression to invasive carcinoma while simple hyperplasia has only $1 \%$ incidence of progression. In general, the basic picture of post-menopausal endometrium is atrophic, the endometrial hyperplasia occurs in the presence of high estrogen concentrations. The presence of functional endometrium in $32 \%$ of our postmenopausal women is a concern. Sharma et al. reported $32.5 \%$ had functional endometrium as cause of PMB. Long term follow up examination of these patients is needed ${ }^{4}$.Endometrial hyperplasia/ proliferative endometrium occurs in $5 \%-10 \%$ of patients with postmenopausal uterine bleeding, mainly due to oestrogen. The source of excess oestrogen should be considered, including obesity, exogenous oestrogen or an oestrogenic-secreting ovarian tumour. Clinically significant hyperplasia usually evolves within a background of proliferative endometrium as a result of protracted oestrogen stimulation in the absence of progesterone influence. Not only is endometrial hyperplasia important because of the possibility of abnormal uterine bleeding but it may also precede or occur simultaneously with endometrial cancer. Postmenopausal bleeding is the most common presenting symptom in women diagnosed with endometrial cancer. In postmenopausal women oestrogen is considered as an established risk factor for endometrial hyperplasia and cancer. ${ }^{19}$

\section{CONCLUSION}

Apart from common benign lesions, carcinoma cervix and carcinoma endometrium are commonly seen in postmenopusal women with complaints of postmenopausal bleeding. Early diagnosis can certify improve quality of life and reduce mortality and morbidity.

\section{REFERENCES}

1. Kothapally K, Bhashyakarla U. Postmenopausal bleeding: clinicopathologic study in a teaching hospital of Andhra Pradesh: IntJ Reprod Contracept Obstet Gynecol. 2013;2(3):344-48.

2. Ubeja A, Singh A. Clinicopathological evaluation of postmenopausal bleeding in rural hospital set up. Int J Reprod Contracept Obstet Gynecol 2017;6:3556-9.

3. Mittra I, Mishra GA, Singh S, Aranke S, Notani P, Badwe R, et al. A cluster randomized, controlled trial of breast and cervix cancer screening in Mumbai, India: Methodology and interim results after three rounds of screening. Int J Cancer 2010;126:976-84.

4. Sharma DD, Chandnani KA. A study of aetiology and prevalence of malignancy in patients with postmenopausal bleeding.
International Journal of Reproduction, Contraception, Obstetrics and Gynecology 2017;6:3973-8.

5. Gandi SR, Vishwekar PS. A study on correlation of Pap smear, colposcopy and colposcopic directed biopsy in women with unhealthy cervix. J. Evolution Med. Dent. Sci. 2017;6(7):515-518.

6. Breijer MC, Timmermans A, van Doorn HC, Mol BW, Opmeer BC. Diagnostic strategies for postmenopausal bleeding. Obstetrics and Gynecology International 2010;2010:850812

7. Kaur M, Singh R, Sharma M. Endovaginal sonographic evaluation of postmenopausal uterine bleeding. Journal of Clinical and Diagnostic Research 2010;(4):2175-82.

8. Kolhe PS. Management of abnormal uterine bleeding e focus on ambulatory hysteroscopy. Int J Womens Health 2018;10:127e36. https://doi.org/10.2147/ IJWH.S98579. Published online 2018 Mar 22.

9. Spiezio Sardo ADS, Calagna G, Carloa CD. Tips and tricks in office hysteroscopy. Gynecol Minim Invasive Ther February 2015;4(1):3e7.

10. Karmakar PJ, Wilkinson A, Rathod M. Histopathological evaluation of postmenopausal bleeding. IOSR J Dent Med Sci 2014;13:53-7.

11. Mallick A, Behera R, Subudhi K. Histopathological study of endometrium in postmenopausal bleeding. J Evol Med Dent Sci 2013;2:9010-8.

12. Aswathy S, Quereshi MA, Kurian B, Leelamoni K. Cervical cancer screening: Current knowledge and practice among women in a rural population of Kerala, India. Indian $\mathrm{J}$ Med Res 2012;136:205-10.

13. Harsha Kumar H, Tanya S. A study on knowledge and screening for cervical cancer among women in Mangalore city. Ann Med Health Sci Res 2014;4:751-6.

14. Dr Pragati J Karmarkar, Dr Anne Wilkinson, Dr Mayuri Rathod Histopathological Evaluation of Postmenopausal Bleeding IOSR Journal of Dental and Medical Sciences Volume 13, Issue 10 Ver. III (Oct. 2014), PP 53-57.

15. Nirupama V, Suneetha Y, Prabha Devi K. PostMenopausal Bleeding: An Analytic Study of 100 Cases. International Journal of Science and Research. 2015:4:2319.

16. Sonali Rathi, Sangeeta K, Manisha K. "Histopathological evaluation in women with Postmenopausal Bleeding and Associated Risk factors for Endometrial Carcinoma". Journal of Evolution of Medical and Dental Sciences 2013; Vol2, Issue 24, June 17;Page:4397-4402.

17. Arati Mallick, Ritanjali Behera, Khetrabasi Subudhi. "Histopathological study of endometrium in postmenopausal bleeding". Journal of Evolution of Medical and Dental Sciences 2013; Vol. 2, Issue 46, November 18; Page: 9010-9018.

18. Van den Bosch T, Ameye L, Van Schoubroeck D, et al. Intracavitary uterine pathology in women with abnormal uterine bleeding: a prospective study of 1220 women. Facts Views Vis Obgyn. 2015;7(1):17-24.

19. Bani-Irshaid 1 and A. Al-Sumadi Histological findings in women with postmenopausal bleeding: Jordanian figuresEastern Mediterranean Health Journal Vol. 17 No. 7, 2011.
Source of Support: None Declared Conflict of Interest: None Declared

\section{Policy for Articles with Open Access}

Authors who publish with MedPulse International Journal of Gynaecology, (Print ISSN: 2579-0870) (Online ISSN: 2636-4719) agree to the following terms: Authors retain copyright and grant the journal right of first publication with the work simultaneously licensed under a Creative Commons Attribution License that allows others to share the work with an acknowledgement of the work's authorship and initial publication in this journal.

Authors are permitted and encouraged to post links to their work online (e.g., in institutional repositories or on their website) prior to and during the submission process, as it can lead to productive exchanges, as well as earlier and greater citation of published work. 